Supporting Information

\title{
Understanding the Effects of Water Molecules on Cyclohexanol Dehydration over Zeolitic Acid Sites
}

\author{
Peng Liu ${ }^{\dagger}$ Wenqi Hao ${ }^{\dagger}$, and Donghai Mei ${ }^{*, \dagger, \ddagger}$ \\ ${ }^{\dagger}$ School of Chemical Engineering and Technology, State Key Laboratory of Separation Membranes and Membrane Processes, Tiangong \\ University, Tianjin 300387, P. R. China \\ School of Environmental Science and Engineering, Tiangong University, Tianjin 300387, P. R. China
}


Table S1. Detailed parameters for coordination numbers.

\begin{tabular}{cccc}
\hline$c n$ & $p$ & $q$ & $r_{\mathbf{0}}$ \\
\hline$c n(\mathrm{C}-\mathrm{H})$ & 6 & 6 & 1.6 \\
\hline$c n(\mathrm{O}-\mathrm{C})$ & 6 & 6 & 2.0 \\
\hline$c n\left(\mathrm{O}-\mathrm{H}_{3}\right)$ & 6 & 6 & 1.6 \\
\hline$c n\left(\mathrm{O}-\mathrm{H}_{\mathbf{B}}\right)$ & 12 & 14 & 1.2 \\
\hline
\end{tabular}

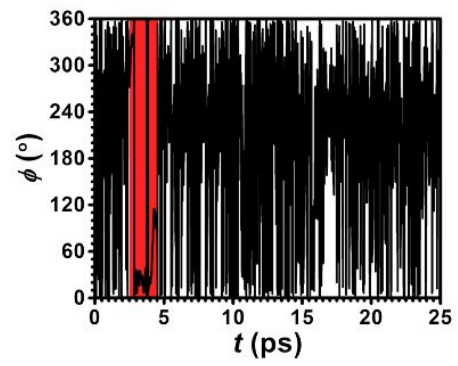

Figure S1. Time evolution of one Cremer-Pople coordinate, $\phi$, characterizing the conformation of cyclohexanol within wet MFI. 


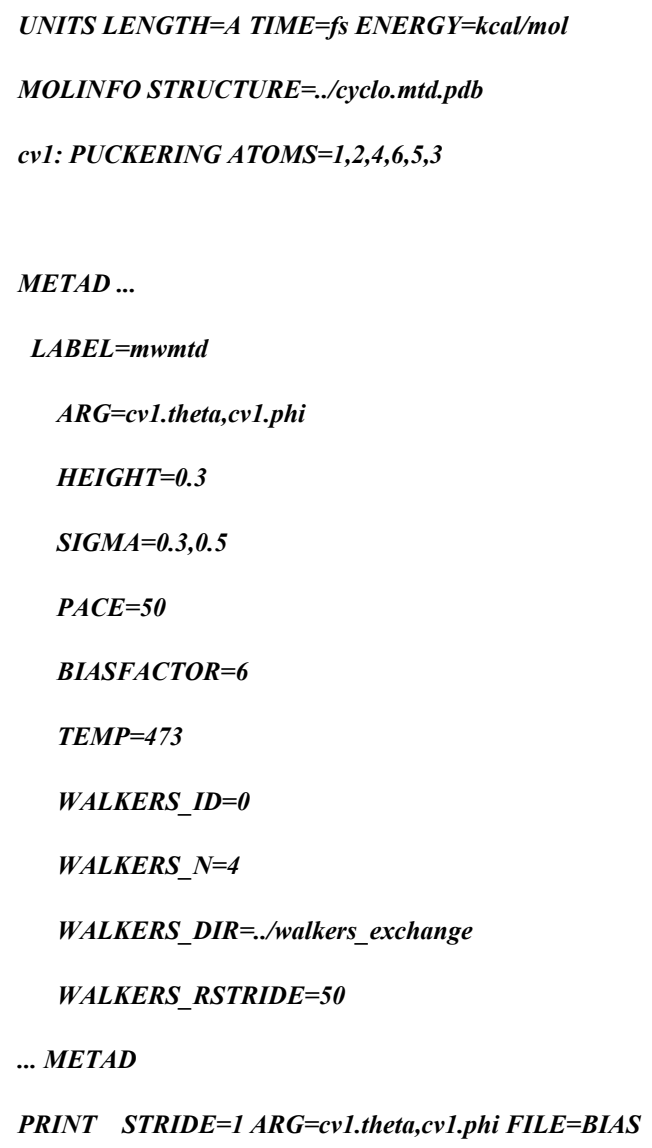


The file of Plumed input for the hydration process of cyclohexanol in the dry H-MFI zeolite.

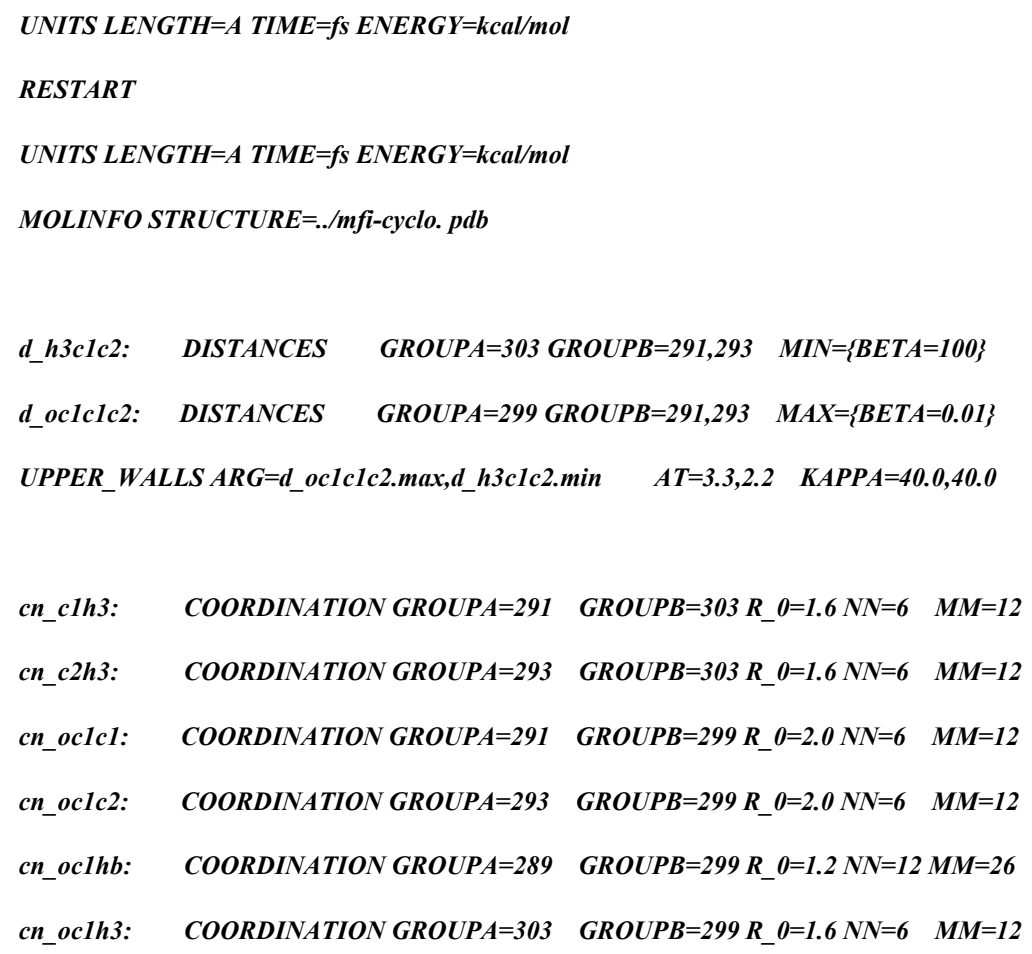


The file of Plumed input for the hydration process of cyclohexanol in the wet H-MFI zeolite.

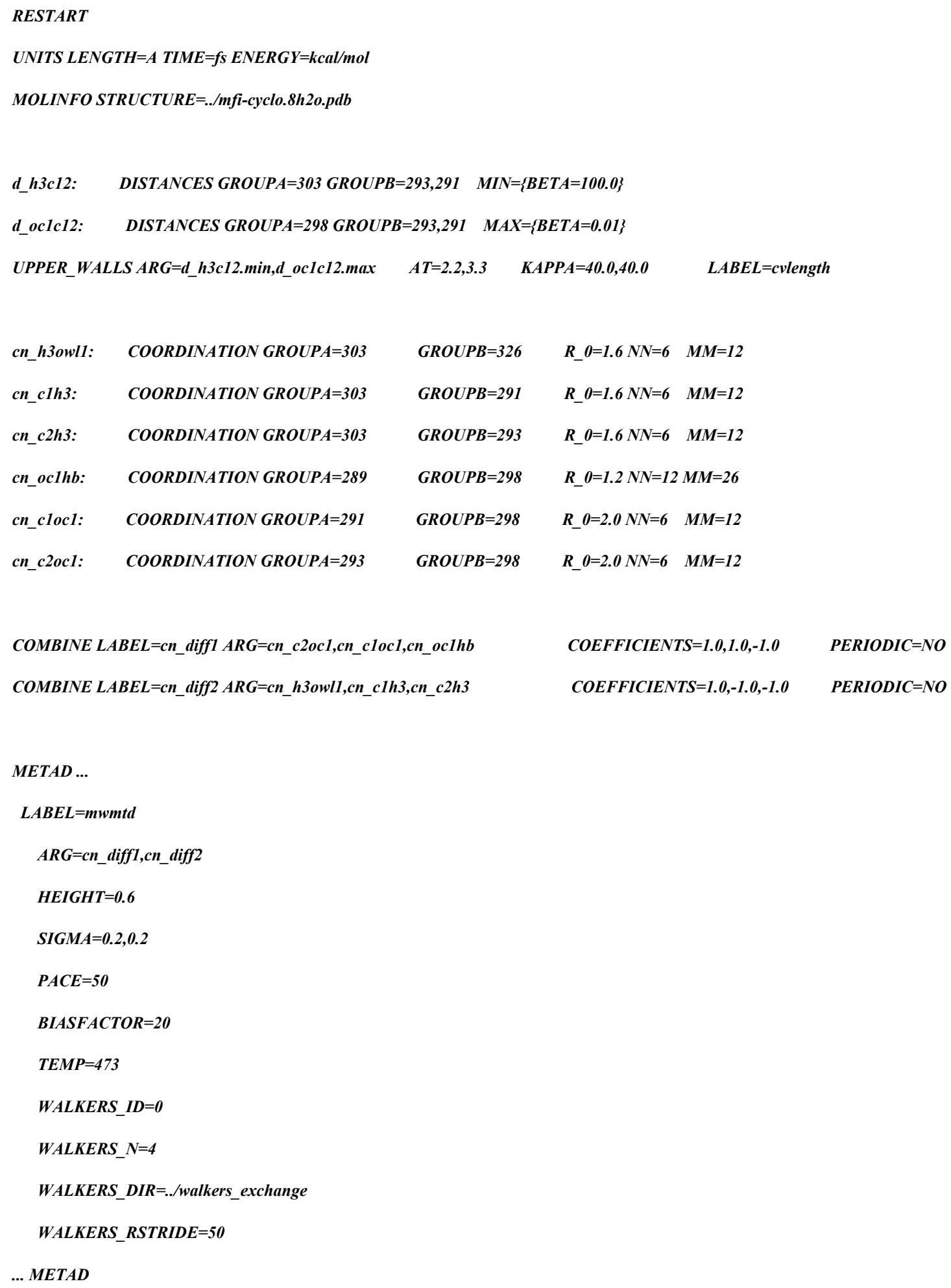

